\title{
Utilization of Emotional Intelligence in the Management of Cultural Change in the High School in China
}

\author{
Meng Fan ${ }^{1,2}$ \\ ${ }^{1}$ School of Foreign Languages, Fuzhou University, Fuzhou, China \\ ${ }^{2}$ Center for Cross-Cultural Discourse Study, Fuzhou University, Fuzhou, China
}

Email address:

adata@sina.com

To cite this article:

Meng Fan. Utilization of Emotional Intelligence in the Management of Cultural Change in the High School in China. International Journal of Secondary Education. Vol. 5, No. 3, 2017, pp. 30-36. doi: 10.11648/j.ijsedu.20170503.11

Received: March 20, 2017; Accepted: April 18, 2017; Published: April 21, 2017

\begin{abstract}
Recent years have seen the school education and management environment become increasingly complex that require high demands for school leaders. Researchers in the field of educational leadership have suggested that emotional intelligence of school leaders will have positive influence over the school operation. The paper has made an effort in critically reflecting a high school headteacher's practice of school cultural change through the application of emotional intelligence. The importance of the research lies in the fact that school culture strongly correlates to school improvement, and it is inevitable to change school culture when it plays the negative effects to the school. Utilization of emotional intelligence in the management of cultural change in the high school in China will be discussed in depth, and implications as well as recommendations will be provided.
\end{abstract}

Keywords: Emotional Intelligence, Cultural Change, Educational Leadership, High School, Headteacher

\section{Introduction}

The term emotional intelligence, popularized by Goleman [1], has attracted researchers' attention from psychological, management and educational areas, and has had a great impact on the study of emotions at work [2-5]. Focusing on the features of emotional intelligence identified by scholars [4-7], the term comprises at least four components: 'self-awareness; awareness of others; regulating emotions; developing emotional literacy'. In this sense, we see that emotional intelligence can be used to deal with individuals' emotions and establish social relationships, which potentially affects organizational functioning and effectiveness in the workplace.

Recent years have seen the school education and management environment become increasingly complex that require high demands for school leaders. Researchers in the field of educational leadership have suggested that emotional intelligence of school leaders will have positive influence over the school operation, such as improving teachers' performance and satisfaction [8-13]. School leaders' high emotional intelligence, as is known as Goleman indicates, may enable teachers to feel that what they do is worthwhile and valued [14]. Accordingly, a motivated workforce can be facilitated and formed with a high achievement drive for the promotion of the school. In this sense, the core of emotional intelligence, deployed to teachers and departments, even across the school as a whole, appears that the school leaders' appropriate application, management and assessment of emotions are critical to school development.

School culture plays a powerful role in school management, such as maintaining the school's stability and enhancing communication between school leaders and teachers [15]. It would be argued that a positive school culture may foster school improvement, teacher development and student achievement; however, a negative school culture may cause hurdles for the development of the school as well [16-20]. Along with the pace of social progress, changes take place all the time, which probably pose challenges to a school's culture [21]. If the culture in the school cannot fit the present social progress, the headteacher may conduct some appropriate changes; otherwise, the improvement of his or her school will possibly be constrained [22]. Therefore, how to effectively and efficiently impose school cultural change by school leaders has become a fashionable topic in 
the field of educational leadership.

The purpose of this article is to understand better how leaders utilize the emotional side of leadership in the management of cultural change in the school. The importance of the research lies in the fact that school culture strongly correlates to school improvement, and it is inevitable to change school culture when it plays the negative effects to the school. Furthermore, there are potential impacts of leaders' emotional intelligence on school management and school effectiveness. Thus, the objective of the study is to discover why change has been so difficult to effect, explore and appraise the application of school leaders' emotional intelligence in addressing the potential barriers in a culture of change for school progress and society's demands, by relating to some relevant theories and researches as well as discussing a particular setting with which the author is familiar as a reflective account.

The following parts will be divided into four parts. Firstly, development of the term emotional intelligence will be reviewed, together with an analysis of educational leadership in imposing school cultural change. There will then be an attempt to reflect a practice of the utilization of emotional intelligence in leading cultural change in a Chinese high school as a case study. Finally, emotional intelligence and educational leadership in China will be discussed in depth, and implications as well as recommendations will be provided in the conclusion.

\section{Literature Review}

\subsection{Development of Emotional Intelligence}

Originally, the term emotional intelligence was referred to deal with emotions by Salovey and Mayer [23], who defined it as 'the ability to monitor one's own and other's feelings and emotions, to discriminate among them and to use this information to guide one's thinking and actions'. However, the term initially attracted less attention. It was not popularized until it was advocated by Goleman [1], who directed considerable attention to the notion and identified core aspects of emotional intelligence, such as self-awareness, emotional management, self-motivation, empathy, and relationship management. As the term has come to be known, Goleman continued to expound emotional intelligence as 'the capacity for recognizing our own feelings and those of others, for motivating ourselves, and for managing emotions well in ourselves and on our relationships' [14]. Hence, in the early stage of theoretical development, scholars inclined to hold a general view of emotional intelligence that it is the competence that might control individuals' emotions and influence personal performance.

In recent years, there has been substantial research attempting to clarify the definition of emotional intelligence and direct some ambitious claims for its efficacy. A consensus appearing to be built by researchers is that emotional intelligence should be an individual's ability to treat emotions and its domain should contain the following four dimensions: (1) Appraisal and expression of emotion in the self; (2) Appraisal and recognition of emotion in others; (3) Regulation of emotion in the self; (4) Use of emotion to facilitate performance. Based on reviewing the relevant literature, the author is in accordance with the four dimensions and deems that individuals who have high levels of emotional intelligence are able to perceive and understand emotion, to integrate it into thought, and to regulate it to influence own and others' performance. I intend to adopt these dimensions as the theoretical framework in this paper to examine and discuss the headteacher's application of emotional intelligence in school management in the context of the Chinese high school.

\subsection{Emotional Intelligence \& Leadership in Organizations}

There is increasing body of knowledge pointing to the significance of emotional side of leadership in the workplace. Cooper and Sawaf propose that emotional intelligence is of importance for leadership to direct staff in organizations as emotions are 'the primary source of motivation, information (feedback), personal power, innovation and influence' [23]. Goleman et al. argue that emotional intelligence is a vital component of leadership effectiveness, particularly when leaders tackle resistant groups [24]. Zeidner et al. also consider emotional intelligence as a critical component of management and work [25]. However, there are some researchers who warn against some of positive claims about emotional intelligence and who remind us that it is difficult to clarify or measure emotional intelligence [26]. Nevertheless, it appears that emotional intelligence at least is a key facet of effective leadership.

Furthermore, studies of leadership have examined a variety of issues related to leadership styles, such as emotions. Transformational leadership, a predominant leadership style at the present, has been identified as an especially powerful source of effective leadership in different organizational contexts in several reviews and meta-analyses [27-28]. Building on acknowledged dimensions of emotional intelligence, recent theoretical and empirical studies reveal that there have been close relationships between emotional intelligence and transformational leadership [29]. Thus, emotional intelligence embedding in transformational leadership comes to improving organizational effectiveness.

\subsection{Headteachers' Emotional Intelligence in the Management of Schools}

Recently, the significance of the emotional dimensions in educational leadership has been widely discussed. Similar to business scholars who have documented the importance of the emotional components in the workplace, researchers in the field of educational leadership have also proposed that school leaders' emotional intelligence will have positive impacts on the school operation [11-12]. James and Vince indicate that headteachers may perform their roles properly by applying varied emotional components towards different stakeholders and staff [30]. Additionally, research on transformational leadership has 
suggested educational leaders to utilize their emotions and morals in positive ways, and has argued that effective leaders have to generate beliefs in a culture of improvement. Therefore, it seems that emotional intelligence could be an essential ingredient for a successful school leader.

\subsection{Emotional Intelligence \& Leadership for School Cultural Change}

School culture has become an area of intense study in the educational field in the last few decades and the recent literature acknowledges a powerful role that the school culture plays in the school setting [19-20]. School culture, influencing school leading ideas, educational thoughts, teaching and learning practice, has the ability both to foster and restrain the individual development within the school [15]. Hence, it could be argued that school effectiveness and improvement is significantly affected by school culture, and thereby changing school culture appears to be necessary when it performs its negative impacts.

Change, which itself is a complex phenomenon, takes place within a social context and is determined through the sophisticated interactions of its members [31]. In the past two decades, the extensive need for change in education has resulted in widespread reconsideration of educational leadership and effective approaches to lead the change [32]. Vince argues that to a great extent, individual and collective emotions affect organizational change [33]. For instance, the change efforts can be prevented and limited for the neglects of how power relations are enacted in an organization and how emotions such as defensiveness, anger and anxiety influence these relations (ibid). In this sense, emotional intelligence, concerning how school leaders handle themselves and others, plays a critical role in the management of change.

Cultural change, a type of change activities, possesses common natures of change as well as its special characteristics. There is prevalent acceptance in the literature that it is difficult to change the organizational culture of an institution. In a culture of change, emotions frequently run high and often represent 'fear or differences of opinion', which is the nature of change [32]. Accordingly, the staff, who often express doubts about new directions and sometimes outright opposition to them, tend to become the resistant group to the change. Maurer points out that 'the only way to deal with resistance is to work with resisters and place emphasis on their emotions' [34]. Thus, school cultural change, which can be unpredictable and disturbing, is a difficult and complex enterprise in school management, yet, emotional intelligence can be a main ingredient of successful leadership for the prospect school cultural change in that school leaders can apply emotional intelligence to effectively deal with resistance in the change.

\section{Investigation and Results}

\subsection{School Background}

The high school involved in the study has been regarded as an outstanding educational institution in this city located in the middle of China. There were, currently, 36 classes with 167 staff and 2,000 students aged between 16-18 in 2015. The challenge for the headteacher was to lead a culture of change in order to facilitate school improvement and adapt to social development in the changing time.

\subsection{The Headteacher's Practice}

The headteacher is of the view that emotions and tensions between teachers and departments need to be considered as an important component of school cultural change. Busher assumes that more successful leaders in the management of change are those who are able to overcome resistances through persuasion, through assuaging individuals' fears, or through cajoling individuals to act in ways they prefer [35]. To deal with resistant group, the headteacher deployed transformational leadership with her emotional intelligence, and thereby achieved a great success as shown in Figure 1.

1) Self-awareness \& awareness of others

The headteacher initially attempted to understand that fear and resistance were natural effects of change as uncertainty raised individuals' tensions and anxiety. Exploring staff's feelings, she identified and analyzed their emotions toward the change. Change normally implies that current working patterns, working environment, and behavior modes will meet a significant challenge. School teachers, especially those who have worked in this school for a long time, were accustomed to doing things in the usual way, and were satisfied with current situation. Thus, they have had a natural reluctance to the change, which itself was a kind of denial of established patterns and habits.

The headteacher continued to perceive that although some teachers recognize that change may bring much more profits and benefits, they would rather maintain their status quo merely because of the formed habits. Some others were lack of conscious recognition to the direction of future development and they could not identify that the current environment had negative impacts on their school, but assumed the working environment was appropriate and it was not imperative to impose any change. If the change affected relevant departments or individuals' benefits, those protecting their profits would tend to resist the change, which might result in readjustment and redistribution of benefits, power and resources in the school. She also recognized that lack communication and information of change might cause some teachers' dissatisfactory and misunderstanding as well.

2) Regulate self emotions \&utilize emotions to facilitate performance

Through listening to the concerns and ideas of teachers whose lives were going to be changed, the headteacher acknowledged the overload, fragmentation, and other stresses that could accompany change initiative. The headteacher addressed these concerns and ideas in public statements, and incorporated these concerns and ideas into the ongoing dialogue about change. Several strategies were deployed in the leading of school cultural change through the influence of emotions, such as strengthening communication with staff, 
inspiring them to participate into decision making and actively engage into change, creating an atmosphere of mutual trust and mutual respect, sharing the risk responsibility and reaching a consensus through openness-discuss differences.

The headteacher gave strong encouragement with awards to credible colleagues about the ability to manage the change and motivated them to impose the change eventually to accomplish the overall aims. The headteacher utilized emotional intelligence to handle stress, showed empathy and became sensitive to teachers' feelings to control their emotions. She regarded open communication as essential for dealing with resistant emotions in the change. Open communication helped her survive a difficult time and protected her when she worked with the colleagues. It often enabled the decisions to feel as if they were all school members' and not just the headteacher's. During the open communication, teachers felt the headteacher has done what was correct, and they have acted in their departments' best interests.

In the educational management field, leadership behaviors which have emotional implications are repeatedly recommended, such as 'lending support, exhibiting moral integrity, providing safety, fostering collaboration, offering intellectual stimulation, practising consultative and shared decision making' [36]. What the headteacher has done in this change process is consistent with the relevant literature. Exploring resisters' intensions, knowing and identifying self-imposed barriers to change and helping teachers to overcome them are crucial stages in the practice. The emotionally intelligent headteacher served as a benefit to her school in two ways. One is that the headteacher motivated teachers to work together toward school goals. The other is that she served as a transformational influence over teachers. In this manner, she challenged her staff to work toward increasing school effectiveness and performance, built interpersonal trust, and inspired them to implement the articulated vision of the change.

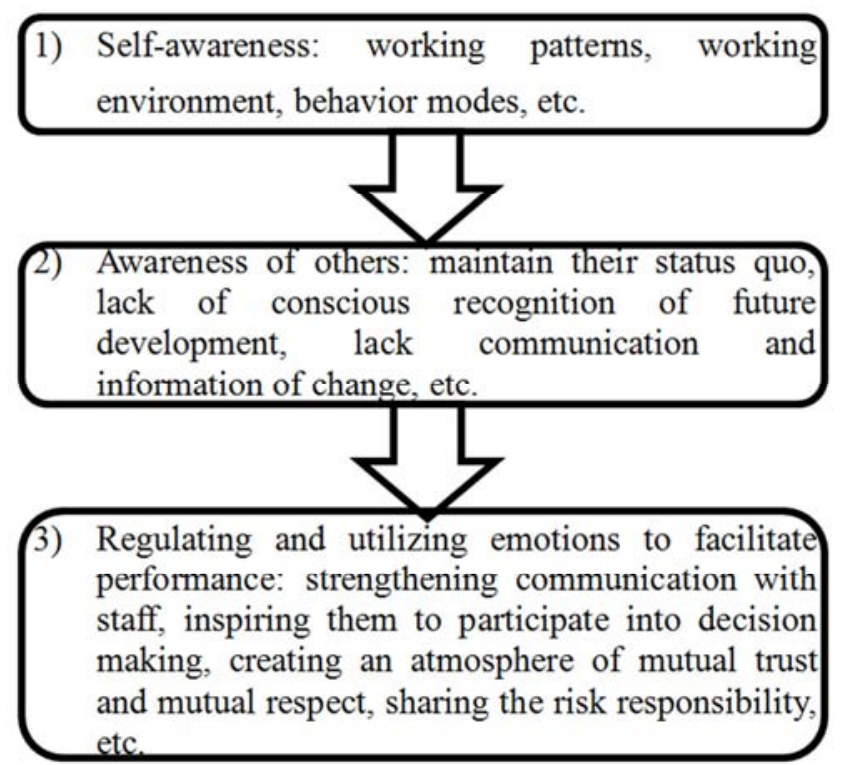

Figure 1. The headteacher's main practice.

\subsection{Staff's Insights into the Change}

Social interactions involve a display of emotions, which in turn have effects on organizational functioning [37]. Within the school, interactions between the headteacher and her staff, which caused a variety of emotions in the changing period, appear to influence the change effectiveness and school functioning. Furthermore, Fullan deems that school change depends on what teachers do and think [32]. Thus, it is worthwhile and valued to reflect and appraise school teachers' insights into the change.

Actually, change does not merely result in resistance, threat and uncertainty, whereas it can be experienced as growth, hope, stimulation and excitement as well [38]. Hence, it is rational that there are different even opposite attitudes towards the cultural change from teachers' perspective. Some of them find the change exciting as they are aware of the limitations in the current context and seek for challenge, while for others the prospect change may be threatening, as they dislike dealing with uncertainty. Those belonging to the resistant group become hurdles to the school cultural change, and thereby the challenge for the headteacher is to find ways of bringing her staff on board and getting them involved in the prospect change.

The teachers' perceptions reveal the recognition of the demands and tensions of their jobs [39]. Therefore, the headteacher drew attention to teachers' insights into the cultural change and accordingly applied different strategies to deal with staff holding varied emotions, especially focused on dealing with the resistant group. In the process, the headteacher encouraged school teachers to participate in decision making, motivated them to make innovation in the teaching and tolerated their mistakes so that teachers might suffer less pressure from the change. Eventually, atmosphere of mutual trust was created and a consensus of opinions of collaborative school culture can be reached.

\section{Discussion}

Studies relating to emotions and organizational changes have largely directed at 'resistance to change'. As an effective leader in a culture of change that was rife with anxiety, stress, and ambiguity, the headteacher deployed her emotional intelligence to appreciate resistance through listening to diverse teachers and departments, acknowledging others' concerns, and inviting them to engage in informed discussion and exploration. As Fan said, change does not only take place for diagnosing and solving a set of occurring problems; it can also be approached by identifying resisters' emotions and the paradoxical relations that challenge the way school leaders think about themselves and the staff [39]. If the headteacher ignored the emotional dimensions of her staff, especially those resisters' in this cultural change, it would be more difficult to impose the change and achieve the final goals.

The headteacher points out that empathy, a component of emotional intelligence, tends to be a critical characteristic 
necessary for school cohesion in the management of cultural change. Empathy is an individual's sensitivity to the feelings and concerns of other social members in human interactions [41]. Transformational leaders need the competency of empathy to display individually considerate behaviors in order to facilitate individuation, mentoring, and development of followers. The headteacher utilizes her empathetic ability to recognize and respond to changes in the emotional states of the teachers. The establishment of empathetic behavior causes relationships between the headteacher and common staff during the culture of change to be built and the organizational support network within the school to be formed. Accordingly, a cohesive bond is created, resulting in the reduction of emotional conflict in school member interactions. Finally, the change can be imposed and conducted more smoothly.

Although there are acknowledged four dimensions in emotional intelligence discussed above in part one, the first three dimensions are the preparation for the fourth one, as the final purpose of the headteacher's application of emotional intelligence is to use and direct emotions toward constructive activities in order to facilitate personal performance in the school cultural change. Indeed, the headteacher performs her high emotional intelligence in the leading of change and obtains anticipated outcomes. However, the change might be imposed more efficiently if she laid more emphasis on strengthening relationships among teachers rather than developing relationships between her and teachers, for raising team spirit, and inspiring teachers' sense of responsibility and sense of belonging could facilitate their interaction dynamics and in turn promote the building of collaborative culture.

Emotional intelligence demonstrates a set of dispositional attributes for monitoring one's own and others' internal states in order to instruct one's and others' thinking and actions and establish harmonious relationships among individuals, which is the basis of the synergistic sharing of skills and competencies of creating and sustaining networks [1]. Increased evidence in recent years seems to manifest that emotional intelligence has emerged as one of the most notable social effectiveness skills which are crucial to the performance and effectiveness of leaders. If a school leader has the abilities of self-awareness and self-regulation, motivation and empathy, leadership skills and open communication skills in the school operation, his or her school will become more resilient, no matter what the future brings.

Educational leadership, seen as one of the most essential factors in school improvement and effectiveness, can provide a culture within which teaching and learning will prosper [37]. The training of leaders has therefore become of paramount importance. Emotional intelligence is a set of acquired skills and competencies that pin down effective leadership and performance. Hence, promoting school leaders' emotional intelligence has been considered as a fascinated direction in headteachers' professional development. The purpose of the training program of emotional intelligence is to foster school leaders to perceive emotion, to integrate it in thought, to understand it, and to manage it. To perform well and be successful in one's professional and personal life apparently demands the ability to make emotionally and socially intelligent decisions, particularly in China where the accepted traditional custom is that individuals incline to build harmonious relationships in social interactions.

However, there are some other researchers who warn against some of prevalent positive claims about emotional intelligence and who remind us that emotional intelligence is difficult to manifest and even harder to measure [26]. Nevertheless, it appears that emotional intelligence is at least an important force within an organization. Therefore, recent years, central government and local authorities in China lay emphasis on training school leaders' emotional intelligence to develop schools and adapt to educational reforms. The training program can provide opportunities of personal development and facilitate school promotion as well. The potential issue, as we see at the present, may be the quality of the program, such as trainers' knowledge of emotional intelligence and trainees' relevant utilization in their schools. However, this will be investigated and discussed in further studies as this program has just emerged and we need time to examine its outcomes.

\section{Conclusion}

The main core of the initial question was: how school leaders use emotional intelligence in the management of school cultural change for school improvement. The importance of the research depends on the fact that changing school culture 'could have the effect of promoting school improvement' [42], and emotional intelligence is an effective and efficient approach in the leadership to influence the management of change [31]. Thus, investigating and appraising how emotional intelligence is deployed to change school culture has become the objective of the study.

Effective leadership in a culture of change is dependent on many of the particular aspects of emotional intelligence, such as being conscious of feelings, knowing the causes of feelings and how they change over time, being able to express and induce feelings in others, and even having the tacit knowledge of how and why emotions are concerned with cultural change [32]. In the leading of school cultural change, the headteacher perceived her internal states and managed own impulses and resources. She was also aware of others' feelings and needs, and develops a rapport with diverse teachers in the school. Conceptually, this study supports the basic idea that the educational leadership requires school leaders to have high levels of emotional intelligence. Practically, this may imply that in selecting, training and developing school leaders, emotional intelligence should be one of the significant concerns.

\section{Recommendations}

Recommendations for further utilization of emotional intelligence in the management of school changes and further 
study focuses of educational leadership are listed below. First, the headteacher might seek for parents' emotions about school management as Carney suggests that closer relationships between parents and schools seem to raise the quality of work in the school [43]. Next, teachers' job satisfaction and motivation should be addressed with school leaders' emotional intelligence since teachers are the key force in the school progress. Moreover, it is timely, even urgent for the headteacher to consider the possible future of the high school and thereby nurture a positive school culture through applying emotional intelligence in order to create a common understanding of the socioeconomic changes affecting it and to help school members propose adequate responses to these changes. In addition, since emotional intelligence plays the powerful role in educational leadership, how to effectively and efficiently foster school leaders' emotional intelligence has become an important task and research focus to educational scholars. Last but not the least, Confucianism, which greatly influences Chinese people's thoughts and behaviors, might also be considered by researchers in the study on school leaders' emotional intelligence to maximize the positive effects of leadership in the Chinese context.

\section{Acknowledgements}

This research received financial support from the Research Project for Young Teachers of Fujian Province (No. JAS160071), and Scientific Research Foundation of Fuzhou University (No. XRC201515).

\section{References}

[1] D. Goleman, Emotional intelligence. New York: Bantam, 1995.

[2] M. A. Glynn, 'Innovative genius: a framework for relating individual and organizational intelligences to innovation', Academy of Management Review, 21(4), 1996, pp. 1081-1111.

[3] S. Stalinski, 'Organizational intelligence: a systems perspective', Organization Development Journal, 22(2), 2004, pp. 55-67.

[4] J. Cliffe, 'Emotional intelligence: a study of female secondary school headteachers', Educational Management Administration \& Leadership, 39, 2011, pp. 205-218.

[5] J. Cliffe, 'Female headship and life history research: using emotional turning points', Creative Education, 7, 2016, pp. 2774-2790.

[6] P. Salovey and J. D. Mayer, 'Emotional intelligence', Imagination, Cognition and Personality, 9(3), 1990, pp. 185-211.

[7] H. Gardner, Intelligence Reframed: Multiple Intelligences for the $21^{\text {st }}$ Century. New York: Basic Book, 1999.

[8] L. Marlow and D. Inman, 'Pro-social literacy: are educators being prepared to teach social and emotional competence?' Paper presented at the $92^{\text {nd }}$ Annual Meeting of the National Council of Teachers of English, 2002. Atlanta, GA.
[9] M. J. Elias, A. Harriett and C. S. Hussey (Eds.) EQ + IQ = Best Leadership Practices for Caring and Successful Schools. Thousand Oaks, CA: Corwin Press, 2003.

[10] G. S. 'Bloom, emotionally intelligent principals: addressing the effective demands of newcomers through one-on-one coaching', School Administrator, 61, 2004, pp. 14-18.

[11] C. Giles and A. Hargreaves, 'The substainability of innovative schools as learning organizations and professional learning communities during standardized reform', Education Administration Quarterly, 42(1), 2006, pp. 124-56.

[12] M. Crawford, 'Rationality and emotion in Primary School Leadership: An Exploration of Key Themes. Educational Review, 59(1), 2007, pp. 87-98.

[13] J. M. Smith, 'Agency and female teachers' career decisions: a life history study of 40 women', Educational Management Administration \& Leadership, 39, 2011, pp. 7-24.

[14] D. Goleman, Working with Emotional Intelligence. London: Bloomsbury Paperbacks, 1999.

[15] M. Y. Gu, 'On the school culture construction', Journal of Southwest China Normal University (Humanities and Social Sciences Edition), 32(5), 2006, pp. 21-25.

[16] J. Prosser (ed.), School Culture. London: Paul Chapman, 1999.

[17] N. Watson, 'Promising practices: what does it really take to make a difference?' Education Canada, 40(4), 2001, pp. 4-6.

[18] Y. C. Cheng, Globalization, localization and individualization of education for the future, in B. Davies and J. West-Burnham, Handbook of educational leadership and management. London: Pearson Education Limited, 2003.

[19] H. Y. Qian, W. Allan and X. Yang, 'Building and leading a learning culture among teachers: a case study of a Shanghai primary school', Educational Management Administration \& Leadership, 45(1), 2017, pp. 101-122.

[20] B. Grobler, C. Moloi and S. Thakhordas, 'Teachers' perceptions of the utilisation of emotional intelligence by their school principals to manage mandated curriculum change processes', Educational Management Administration \& Leadership, 45(2), 2017, pp. 336-355.

[21] P. Dalin and H. Rolff, Changing the School Culture. London: Cassell, 1993.

[22] Z. H. Wu, School Management Theory and Practice. Beijing: Beijing Normal University Press, 2002.

[23] R. Cooper and A. Sawaf, Executive EQ: Emotional Intelligence in Leadership and Organizations. New York: Grosset/Putnam, 1996.

[24] D. Goleman, R. Boyatzis and A. McKee, Primal leadership: Realizing the power of emotional intelligence. Boston: Harvard Business School Press, 2002.

[25] M. Zeidner, G. Matthews and R. D. Roberts, 'Emotional intelligence in the workplace: A critical review', Applied Psychology, 53 (3), 2004, pp. 371-399.

[26] R. D. Roberts, M. Zeidner and G. Matthews, 'Does emotional intelligence meet traditional standards for an intelligence? Some new data and conclusions', Emotion, 1 (3), 2001, pp. 196-231. 
[27] C. Patterson, J. B. Fuller, K. Keste and D. Y. Stringer, 'A meta-analytic examination of leadership style and selected compliance outcomes', Paper presented at the Society for Industrial and Organizational Psychology, 1995, Orlando, FL.

[28] K. S. Law, C. S. Wong and L. Song, 'Construct validity of emotional intelligence: its potential utility of management studies', Journal of Applied Psychology, 89(3), 2004, pp. 483-496.

[29] L. Spano-Szekely, M. Griffin, J. Clavelle and J. Fitzpatrick, 'Emotional intelligence and transformational leadership in nurse managers', Journal of Nurse Administration, 46(2), 2016, pp. 101-108.

[30] C. James and R. Vince, 'Developing the leadership capability of headteachers', Educational Management Administration \& Leadership, 29(3), 2001, pp. 307-317.

[31] R. Pu, Educaonal Administration. Beijing: Renmin University of China Press, 2007.

[32] M. Fullan, Principals in a culture of change. In B. Davies and J. West-Burnham, Handbook of Educational Leadership and Management. London: Pearson Education Limited, 2003.

[33] R. Vince, 'Power and emotion in organizational learning', Human Relations, 54(10), 2001, pp. 1325-1351.

[34] R. Maurer, Beyond the Wall of Resistance. Austin, Tex.: Bard Books, 1996.

[35] H. Busher, 'Schools, effectiveness and improvement, a political analysis', in N. Bennett and A. Harris (eds), School Effectiveness and School Improvement: Searching for the Elusive Partnership. London: Cassell, 2011.

[36] K. A. Leithwood, D. Jantzi and R. Steinbach, Changing Leadership for Changing Times. Buckingham: Open University Press, 1999.

[37] G. R. Fan, Theory and Practice of School Management. Shanghai: East China Normal University Press, 2003.

[38] E. P. Antonacopoulou and Y. Gabriel, 'Emotion, learning and organizational change: Towards an integration of psychoanalytic and other perspectives', Journal of Organizational Change Management, 14(5), 2001, pp. $435-451.9$

[39] C. Day, A. Harris, M. Hadfield, H. Toley and J. Beresford, Leading Schools in Times of Change. Berkshire: Open University Press, 2003.

[40] P. Atkinson, 'Managing resistance to change', Management Services, 49(1), 2005, pp. 14-19.

[41] J. M. George, 'Emotions and leadership: The role of emotional intelligence', Human Relations, 55(8), 2000, pp. 1027-1044.

[42] A. Hargreaves, 'Renewal in the age of paradox', Educational Leadership, 52(7), 1995, pp. 14-19.

[43] F. Carney, More Parental Rapport, Times Educational Supplement. London: Cassell, 2004. 